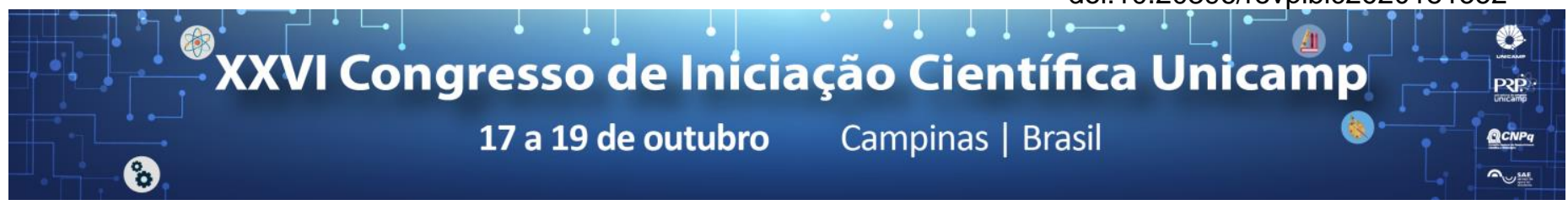

\title{
Estudo da geração de energia elétrica pelo efeito piezelétrico direto
}

\author{
Vinícius D. Galafasse*, Francisco J. Arnold.
}

\section{Resumo}

A crescente busca por fontes sustentáveis de geração de energia elétrica engloba os transdutores piezelétricos como uma alternativa para aplicações discretas, em pequena ou grande escala. Este trabalho consiste no desenvolvimento de uma estrutura assoalho, utilizando conjuntos de cerâmicas piezelétricas como pilares para apoio de carga. Circuitos eletrônicos baseados no C.I. MAX666 são usados para coletar e converter a energia gerada pelas cerâmicas, fornecendo tensão contínua de saída para posterior armazenamento em um capacitor.

\section{Palavras-chave:}

Energia, eletrônica, piezelétrico.

\section{Introdução}

Os materiais piezelétricos, sejam de cristais com o efeito natural ou artificial, possuem a propriedade de conversão de trabalho mecânico em tensão elétrica, e vice-versa. Para este trabalho, foi utilizado o efeito piezelétrico direto como possível fonte de energia sustentável. [1]

É possível excitar um transdutor piezelétrico em diferentes eixos, obtendo-se resultados de acordo com os coeficientes determinísticos de cada material. O coeficiente piezelétrico é a razão entre a deformação de um eixo e o campo elétrico orientado ao longo dos eixos.

\section{Resultados e Discussão}

As cerâmicas utilizadas no projeto são do tipo anular, com dimensões $6,3 \mathrm{~mm}$ altura, $6,3 \mathrm{~mm}$ de raio interno e $19,0 \mathrm{~mm}$ de raio externo. Devido a sua forma, foi usado o coeficiente piezelétrico $\mathrm{d}_{33}$, na orientação do eixo longitudinal. As equações para tal modo de operação são: $S_{3}=\left(1 / Y E_{3}\right) T_{3}+d_{33} E_{3} \quad(1), D_{3}=d_{33} T_{3}+\varepsilon^{T}{ }_{33} E_{3} \quad$ (2), onde $S$ é a deformação mecânica $(\mathrm{m} / \mathrm{m})$, $D$ é o deslocamento elétrico $\left(\mathrm{C} / \mathrm{m}^{2}\right)$, T é a tensão mecânica $\left(\mathrm{N} / \mathrm{m}^{2}\right)$, d é 0 coeficiente piezelétrico $(\mathrm{C} / \mathrm{N})$, E é o campo elétrico $(\mathrm{V} / \mathrm{m})$, $\varepsilon$ é a permissividade elétrica $(\mathrm{F} / \mathrm{m})$, e $\mathrm{Y}$ é o módulo de Young $\left(\mathrm{N} / \mathrm{m}^{2}\right)$.

Para determinar $0 \mathrm{~d}_{33}$ foi realizado um ensaio de caracterização com a prensa MTS Sintech 5/G e um circuito condicionador de carga à base de um amplificador operacional como buffer de sinal, e um

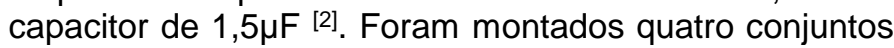
compostos por duas cerâmicas eletricamente em paralelo e mecanicamente em série, verticalmente, conectadas por eletrodos e comportadas por estruturas de alumínio com superfície de contato de mesma área, e testados com carga crescente de 50 a $1300 \mathrm{~kg}$. Os resultados experimentais são mostrados na Tabela 1 .

Tabela 1. d d médio de cada cerâmica por conjunto (pC/N).

\begin{tabular}{|c|c|c|c|}
\hline Conjunto 1 & Conjunto 2 & Conjunto 3 & Conjunto 4 \\
\hline 494 & 652 & 668 & 584 \\
\hline
\end{tabular}

Para a coleta e refinamento da energia gerada pelos conjuntos, foi usado o circuito proposto por Kymissis [3] por auto alimentação do CI MAX666, porém com o diodo zener de 6,3V.

Para o teste de campo com todos os conjuntos atuando, foi construída uma caixa de madeira na qual todo o peso é sustentado internamente pelas peças de alumínio e a carga total é transferida e somada em um capacitor de $500 \mu \mathrm{F}$ através de um circuito retificador.

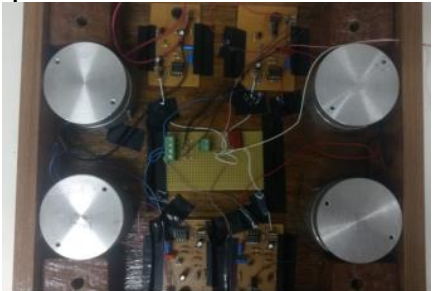

Figura 1. Disposição interna dos componentes dentro da caixa. Ao centro, o circuito retificador com o capacitor.

Em ensaios preliminares foi medido o armazenamento máximo de carga numa sequência de saltos feitos por uma pessoa de $75 \mathrm{~kg}$ por um período de 1 minuto. A carga líquida obtida deve-se à taxa de perda de tensão da descarga do capacitor, uma vez que não há um circuito para impedir ou atrasar tal processo.

Tabela 2. Dados obtidos dos ensaios com a caixa.

\begin{tabular}{|c|c|c|c|}
\hline Impacto(N) & Pressão(Pa) & $\begin{array}{c}\text { Tensão } \\
\operatorname{Max}(\mathrm{V})\end{array}$ & $\begin{array}{c}\text { Taxa de } \\
\text { queda(V/s) }\end{array}$ \\
\hline 1225 & 952,4 & 0,522 & $-0,062$ \\
\hline
\end{tabular}

\section{Conclusões}

Foram caracterizados quatro conjuntos de cerâmicas piezelétricas anulares, obtendo-se o valor médio de 599,5 pC/N. Os valores obtidos para d 33 são elevados em comparação com outros materiais piezelétricos e indicam adequação das cerâmicas utilizadas para sistemas de colheita de energia. Após algumas repetições do ensaio, obteve-se o valor máximo atingido de $522 \mathrm{mV}$ armazenados no capacitor, o que poderia ser otimizado com o acréscimo de um mecanismo de chave por transistores para impedir a perda de carga durante períodos ociosos, ou entre os impactos.

\section{Agradecimentos}

Ao orientador Francisco J. Arnold, pelo grande empenho e ajuda na elaboração deste trabalho.

À Faculdade de Tecnologia - Unicamp, pelo ambiente e estudos que permitiram esta oportunidade.

${ }^{1}$ T. Scalet, Contribuições para Geração e Armazenamento Eficiente de Energia Elétrica Usando Dispositivos Piezelétricos, Dissertação de mestrado Faculdade de Tecnologia - UNICAMP, 2016.

${ }^{2}$ F. J. Arnold, S. S. Mühlen, The resonance frequencies on mechanically prestressed ultrasonic piezotransducers, Ultrasonics 39 (2001) 1-5.

3 J. Kymissis, C. Kendall, J. Paradiso, N. Gershenfeld, Parasitic Power Harvesting in Shoes, Second International Symposium on Weareable Computers, 8pp., 1998. 